\title{
A Biomimetic Enantioselective Approach to the Decahydroquinoline Class
} of Dendrobatid Alkaloids**

\author{
Mercedes Amat*, Rosa Griera, Robert Fabregat, Elies Molins, and Joan Bosch*
}

* ["] Prof. Dr. M. Amat, ${ }^{*}$ Dr. R. Griera, R. Fabregat, Prof. Dr. J. Bosch* $^{*}$

Laboratory of Organic Chemistry, Faculty of Pharmacy, and Institute of Biomedicine (IBUB),

University of Barcelona

Av. Joan XXIII s/n, 08028-Barcelona (Spain)

Fax: (+34)93-402-45-39

E-mail: amat@ub.edu

joanbosch@ub.edu

www.ub.edu/farmaco/grupos/amatbosch/indice.htm

\section{Dr. E. Molins}

Institut de Ciència de Materials de Barcelona (CSIC)

Campus UAB,

08193-Cerdanyola (Spain)

[**] Financial support from the Ministry of Science and Technology (Spain)-FEDER (Project CTQ200602390/BQU) and the DURSI, Generalitat de Catalunya (Grant 2005SGR-0603) is gratefully acknowledged.

Supporting information for this article (experimental details, and copies of ${ }^{1} \mathrm{H}$ and ${ }^{13} \mathrm{C}$ NMR spectra) is available on the WWW under http://www.angewandte.org or from the author.

Frogs of the neotropical family Dendrobatidae produce a remarkably diverse array of biologically active alkaloids. One of the major classes of these amphibian alkaloids ${ }^{[1]}$ are the decahydroquinolines, which have been isolated not only from skin extracts of dendrobatid and mantelline frogs ${ }^{[2]}$ but also from bufonid toads, ${ }^{[3]}$ tunicates, ${ }^{[4]}$ marine flatworms, ${ }^{[4 b]}$ and myrmicine ants. ${ }^{[5]}$ They possess either a cis or trans decahydroquinoline ring fusion, with a side chain substituent at both the C-2 and C-5 positions and, in the lepadin series, ${ }^{[4]}$ an acylated hydroxy group at the $\mathrm{C}-3$ position. The most representative decahydroquinoline alkaloid is cis-195A (formerly called pumiliotoxin C), first isolated in 1969 from a Panamanian population of Dendrobates pumilio. ${ }^{[6]}$

The source of amphibian alkaloids remains an unresolved and challenging question, ${ }^{[1]}$ in particular after the discovery that some of these alkaloids also occur in ants, thus strengthening a dietary hypothesis for their origin in frogs. ${ }^{[5]}$ Although there are no conclusive studies concerning the biosynthesis of these toxins and, consequently, little is known about the biosynthetic pathways, there has been speculation as to possible derivation from the polyketide route by aminocyclization of polycarbonyl intermediates (A), leading to either 2,5-disubstituted decahydroquinolines (C) or spiropiperidines (histrionicotoxins). ${ }^{[1 \mathrm{a}, \mathrm{b}, 7]}$ In accordance with this hypothesis, a plausible biosynthetic pathway to the decahydroquinoline class of dendrobatid alkaloids is depicted in Scheme 1. ${ }^{[8]}$
The structural diversity and pharmacological activity associated with this class of alkaloids, as well as the limited amounts available from natural sources, have stimulated considerable synthetic effort in this area ${ }^{[9]}$ including some biomimetic approaches. ${ }^{[10]}$ In this context we present herein a biomimetic enantioselective approach to the decahydroquinoline class of dendrobatid alkaloids, which has culminated in the biomimetic synthesis of (-)-pumiliotoxin C. ${ }^{[11]}$

Our synthetic approach involves the use of an appropriate 1,5polycarbonyl derivative as a synthetic equivalent of the hypothetical biogenetic polyketide intermediate $\mathbf{A}$ and $(R)$-phenylglycinol as a chiral latent form of ammonia to induce the key enantioselective biomimetic aminocyclization to the target hydroquinoline system.

To evaluate the feasibility of our proposal, we initially used 1,5tetracarbonyl compound 2 [A: $\mathrm{R}^{1}=\mathrm{OEt} ; \mathrm{R}^{2}=\left(\mathrm{CH}_{2}\right)_{3} \mathrm{CO}_{2} \mathrm{Et}$ ], which was easily accessible in excellent yield $(82 \%)$ by reaction of glutaryl dichloride with 4-ethoxy-4-oxobutylzinc bromide (1) in the presence of $\mathrm{Pd}\left(\mathrm{PPh}_{3}\right)_{4}$ as the catalyst (Scheme 2).

To our delight, heating a benzene solution of $\mathbf{2}$ and $(R)$ phenylglycinol under Dean-Stark conditions in the presence of a catalytic amount of $\mathrm{AcOH}$, resulted in the straightforward construction of the hydroquinoline ring system, with generation of two stereogenic centers, leading directly to the enantiopure tricyclic lactam 3 in 35\% yield. Cyclohexenone 4 (22\%) and hydroquinolone 5 (25\% yield; nearly equimolecular mixture of stereoisomers) were also isolated. Formation of $\mathbf{3}$ can be rationalized by considering that, after an initial aldol cyclization from the symmetrical starting diketone $\mathbf{2}$, the resulting $\delta$-oxoester $\mathbf{4}$ undergoes a phenylglycinolpromoted cyclocondensation reaction, in a process that mimics the proposed biosynthetic pathway depicted in Scheme 1. In accordance with this interpretation, 2 was first cyclized to cyclohexenone $\mathbf{4}$ in excellent yield (90\%), by treatment with $1 \mathrm{~N}$ aqueous $\mathrm{LiOH}$ followed by reesterification, and then converted to lactam 3 (60\% yield) by reaction with $(R)$-phenylglycinol in refluxing $\mathrm{C}_{6} \mathrm{H}_{6}$-cat $\mathrm{AcOH}{ }^{[12]} \mathrm{On}$ the other hand, the formation of $\mathbf{5}$ in the direct reaction of $\mathbf{2}$ with $(R)$ phenylglycinol is a consequence of the initial generation of an oxazolidine, which then undergoes two successive cyclizations as depicted in Scheme 3.

By choosing the appropriate 1,5-polycarbonyl derivative, the above biomimetic double cyclocondensation can be adapted to the enantioselective synthesis of a variety of 2,5-disubstituted decahydroquinoline derivatives, as exemplified by the synthesis of the decahydroquinoline alkaloid cis-195A outlined in Scheme 4. The required diketoester 6 was prepared in $65 \%$ yield by Pd-catalyzed coupling of 5-oxohexanoyl chloride with the functionalized organozinc derivative $\mathbf{1}$ and stereoselectively converted as in the above series to a tricyclic hydroquinolone lactam (8) in excellent overall yield. Thus, the initial aldol cyclocondensation took place in 
$85 \%$ yield, whereas cyclocondensation of the resulting cyclohexenone 7 with $R$-phenylglycinol led to lactam 8 in $70 \%$ yield in a process again involving the generation of two stereogenic centers from an achiral precursor. ${ }^{[12]}$ In this series the configuration of the stereogenic ring fusion carbons generated in this step was unambiguously established by X-ray crystallographic analysis ${ }^{[13]}$ of perhydroquinoline $\mathbf{9}$, which was stereoselectively obtained in nearly quantitative yield by catalytic hydrogenation of $\mathbf{8}$. The X-ray structure of 9 also made evident the trans relationship between the hydrogens at the $4 \mathrm{a}$ and 5 positions of the quinoline ring.

The lactam carbonyl present in tricyclic lactam 9 allows the introduction of substituents at the 2-position of the hydroquinoline ring, ultimately leading to enantiopure 2,5-disubstituted cisperhydroquinolines. Thus, 9 was converted to the corresponding thioamide, which was then subjected to Eschenmoser sulfide contraction ${ }^{[14]}$ conditions $\left(\mathrm{BrCH}_{2} \mathrm{CO}_{2} \mathrm{Me}, \mathrm{CHCl}_{3}\right.$; then $(\mathrm{MeO})_{3} \mathrm{P}$, $\mathrm{Et}_{3} \mathrm{~N}, \mathrm{CHCl}_{3}$, reflux) to give $\beta$-enamino ester $\mathbf{1 0}$ in $50 \%$ overall yield.

At this point the complete relative stereochemistry of the target alkaloid cis-195A (pumiliotoxin $\mathrm{C}$ ) was installed by hydrogenation of $\mathbf{1 0}$ in the presence of $\mathrm{PtO}_{2}$ under acidic conditions, which brought about both the stereoselective reduction of the vinylogous urethane double bond and cleavage of the oxazolidine $\mathrm{C}-\mathrm{O}$ bond. A subsequent debenzylation with hydrogen and $\mathrm{Pd}(\mathrm{OH})_{2}$ in the presence of $\mathrm{Boc}_{2} \mathrm{O}$ led to the protected cis-perhydroquinoline $\mathbf{1 1}$.

Finally, the conversion of ester $\mathbf{1 1}$ to pumiliotoxin $\mathrm{C}$ was accomplished in satisfactory overall yield by reduction to alcohol 12, followed by methylenation of the corresponding aldehyde, subsequent catalytic hydrogenation of the resulting $\mathrm{N}$-Boc-2allylperhydroquinoline, and finally deprotection of the piperidine nitrogen. The NMR data and $[\alpha]_{\mathrm{D}}{ }^{22}$ value $(-15.3, c=0.5$ in $\mathrm{MeOH})$ of cis-195A (pumiliotoxin C) hydrochloride were coincident with those reported in the literature. ${ }^{[11]}$

The above results significantly expand the scope and potential of phenylglycinol-derived oxazolopiperidone lactams as chiral building blocks for the enantioselective synthesis of complex piperidinecontaining derivatives. ${ }^{[15]}$ These lactams are easily accessible by a cyclocondensation reaction of a $\delta$-oxoacid derivative with phenylglycinol. The use of diketo(di)esters $\mathbf{2}$ and $\mathbf{6}$ as the $\delta$-oxoester partners in the cyclocondensation reactions reported herein allows the straightforward construction of the hydroquinoline ring system. These 1,5-polycarbonyl derivatives mimic the biogenetic intermediates A (Scheme 1) by undergoing a biomimetic double cyclization that reproduces the key step of the biosynthesis of the decahydroquinoline class of dendrobatid alkaloids.

Received: ((will be filled in by the editorial staff))

Published online on ((will be filled in by the editorial staff))

[1] a) B. Witkop, E. Gössinger in The Alkaloids, Vol. 21, (Ed.: A. Brossi), Academic Press, New York, 1983, pp. 139-253; b) J. W. Daly, T. F. Spande in Alkaloids: Chemical and Biological Perspectives, Vol. 4, (Ed.: S. W. Pelletier), Wiley, New York, 1986, pp. 1-274; c) J. W. Daly, H. M. Garraffo, T. F. Spande in The Alkaloids, Vol. 43, (Ed.: G. A. Cordell), Academic Press, San Diego, 1993, pp. 185-288; d) J. W. Daly in The Alkaloids, Vol. 50, (Ed.: G. A. Cordell), Academic Press, New York, 1998, pp. 141-169; e) J. W. Daly, H. M. Garraffo, T. F. Spande in Alkaloids: Chemical and Biological Perspectives, Vol. 13, (Ed.: S. W. Pelletier), Pergamon Press, New York, 1999, pp. 1-161; f) J. W. Daly, T. F. Spande, H. M. Garraffo, J. Nat. Prod. 2005, 68, 15561575.

[2] a) T. Tokuyama, N. Nishimori, I. L. Karle, M. W. Edwards, J. W. Daly, Tetrahedron 1986, 42, 3453-3460; b) T. Tokuyama, T. Tsujita, A. Shimada, H. M. Garraffo, T. F. Spande, J. W. Daly, Tetrahedron 1991, 47, 5401-5414; c) H. M. Garraffo, J. Caceres, J. W. Daly, T. F. Spande,
N. R. Andriamaharavo, M. Andriantsiferana, J. Nat. Prod. 1993, 56, 1016-1038.

[3] H. M. Garraffo, T. F. Spande, J. W. Daly, A. Baldessari, E. G. Gros, J. Nat. Prod. 1993, 56, 357-373.

[4] a) B. Steffan, Tetrahedron 1991, 47, 8729-8732; b) J. Kubanek, D. E. Williams, E. Dilip de Silva, T. Allen, R. J. Andersen, Tetrahedron Lett. 1995, 36, 6189-6192; c) R. A. Davis, A. R. Carroll, R. J. Quinn, J. Nat. Prod. 2002, 65, 454-457; d) A. D. Wright, E. Goclik, G. M. König, R. Kaminsky, J. Med. Chem. 2002, 45, 3067-3072.

[5] a) T. F. Spande, P. Jain, H. M. Garraffo, L. K. Pannell, H. J. C. Yeh, J. W. Daly, S. Fukumoto, K. Imamura, T. Tokuyama, J. A. Torres, R. R. Snelling, T. H. Jones, J. Nat. Prod. 1999, 62, 5-21; b) T. H. Jones, J. S. T. Gorman, R. R. Snelling, J. H. C. Delabie, M. S. Blum, H. M. Garraffo, P. Jain, J. W. Daly, T. F. Spande, J. Chem. Ecol. 1999, 25, 1179-1193; c) J. W. Daly, H. M. Garraffo, P. Jain, T. F. Spande, R. R. Snelling, C. Jaramillo, A. S. Rand, J. Chem. Ecol. 2000, 26, 73-85.

[6] J. W. Daly, T. Tokuyama, G. Habermehl, I. L. Karle, B. Witkop, Liebigs Ann. Chem. 1969, 729, 198-204.

[7] a) E. Winterfeldt, Heterocycles 1979, 12, 1631-1650; b) U. Scholz, E. Winterfeldt, Nat. Prod. Rep. 2000, 17, 349-366.

[8] For leading references on alkaloids not derived from amino acids, see: a) I. W. Southon, J. Buckingham, Dictionary of Alkaloids, Chapman and Hall, London, 1989, p. xviii; b) P. Dewick, Medicinal Natural Products. A Biosynthetic Approach, 2nd ed, Wiley, Chichester, 2002, p. 38.

[9] For a review, see: C. Kibayashi, S. Aoyagi in Studies in Natural Products Chemistry, Vol. 19, (Ed.: Atta-ur-Rahman), Elsevier Science B. V., Netherland, 1997, pp. 3-88.

[10] a) M. Glanzmann, C. Karalai, B. Ostersehlt, U. Schön, C. Frese, E. Winterfeldt, Tetrahedron 1982, 38, 2805-2810; b) M. Bonin, J. Royer, D. S. Grierson, H.-P. Husson, Tetrahedron Lett. 1986, 27, 1569-1572. For reviews, see: c) K. C. Nicolau, T. Montagnon, S. A. Snyder, Chem. Commun. 2003, 551-564; d) M. C. de la Torre, M. A. Sierra, Angew. Chem. 2004, 116, 162-184; Angew. Chem. Int. Ed. 2004, 43, 160-181. See also reference $7 b$.

[11] For previous enantioselective syntheses of cis-195A [(-)-pumiliotoxin C], see: a) W. Oppolzer, E. Flaskamp, Helv. Chim. Acta, 1977, 60, 204-207; b) S.-I. Murahashi, S. Sasao, E. Saito, T. Naota, Tetrahedron 1993, 49, 8805-8826; c) D. L. Comins, A. Dehghani, J. Chem. Soc. Chem. Commun. 1993, 1838-1839; d) M. Naruse, S. Aoyagi, C. Kibayashi, J. Chem. Soc. Perkin Trans. 1, 1996, 1113-1124; e) T. Riechers, H. C. Krebs, R. Wartchow, G. Habermehl, Eur. J. Org. Chem. 1998, 2641-2646; f) T. G. Back, K. Nakajima, J. Org. Chem. 1998, 62, 6566-6571; g) W. Oppolzer, E. Flaskamp, L. W. Bieber, Helv. Chim. Acta, 2001, 84, 141-145; h) E. W. Dijk, L. Panella, P. Pinho, R. Naasz, A. Meetsma, A. J. Minnaard, B. L. Feringa, Tetrahedron 2004, 60, 9687-9693. For the synthesis of (+)-pumiliotoxin C, see: i) R. K. Dieter, J. R. Fishpaugh, J. Org. Chem. 1983, 48, 4441-4444; j) A. G. Schultz, P. J. McCloskey, J. J. Court, J. Am. Chem. Soc. 1987, 109, 6493-6502; k) M. Toyota, T. Asoh, M. Matsuura, K. Fukumoto, J. Org. Chem. 1996, 61, 8687-8691.

[12] Minor amounts $(\sim 18 \%)$ of the diastereoisomer at the hydroquinoline ring fusion positions were also isolated.

[13] The experiment was done on a Enraf-Nonius CAD4 diffractometer using graphite monochromated Mo $\mathrm{K} \alpha$ radiation. The structure was solved by direct methods (SHELXS-86) after applying Lorentz, polarization, and absorption (empirical PSI scan method) corrections. Full matrix least squares refinement (SHELXL-93) using anisotropic thermal parameters for non- $\mathrm{H}$ atoms and riding thermal parameters for $\mathrm{H}$ atoms (positioned at calculated positions) converged to a $R$ factor of 0.0294 (calculated for the reflections with $I>2 \sigma(I)$ ). Crystal data: $\mathrm{C}_{18} \mathrm{H}_{23} \mathrm{NO}_{2}$, orthorhombic, space group $P 2{ }_{1} 2_{1} 2_{1}, a=7.863(6), b=$ 13.811(9), $c=14.249$ (9) $\AA, V=1547.4(18) \AA^{3}, \mu \square \square$ Mo K $\square \square=0.079$ $\mathrm{mm}^{-1}, D_{\mathrm{c}}=1.225 \mathrm{mg} / \mathrm{m}^{3}$. Approximate dimensions: $0.52 \times 0.48 \times 0.39$ $\mathrm{mm}^{3}$. Data collection was up to a resolution of $2 \theta=49.9^{\circ}$ producing 1795 reflections. Maximum and minimum heights at the final difference Fourier synthesis were 0.080 and -0.097 e. $\AA^{-3}$. CCDC 671493 (9) contains the supplementary crystallographic data for this paper. These data can be obtained free of charge from the Cambridge Crystallographic Data Centre via www.ccdc.cam.ac.uk/data_request/cif.

[14] K. Shiozaki, in Comprehensive Organic Synthesis, Vol 2, (Ed.: B. M. Trost), Pergamon Press, Oxford, 1991, pp. 865-892. 
[15] For a recent review, see: a) C. Escolano, M. Amat, J. Bosch, Chem. Eur. J. 2006, 12, 8198-8207. For more recent work, see: b) M. Amat, C. Escolano, O. Lozano, A.Gómez-Esqué, R. Griera, E. Molins, J. Bosch, J. Org. Chem. 2006, 71, 3804-3815; c) M. Amat, O. Bassas, N. Llor, M. Cantó, M. Pérez, E. Molins, J. Bosch, Chem. Eur. J. 2006, 12, 78727881; d) M. Amat, O. Lozano, C. Escolano, E. Molins, J. Bosch, J. Org. Chem. 2007, 72, 4431-4439; e) M. Amat, M. M. M. Santos, O. Bassas, N. Llor, A. Gómez-Esqué, E. Molins, S. M. Allin, V. McKee, J. Bosch, J. Org. Chem. 2007, 72, 5193-5201; e) M. Amat, M. M. M. Santos, A. M. Gómez, D. Jokic, E. Molins, J. Bosch, Org. Lett. 2007, 9, 29072910.

Scheme 1. A hypothetical biosynthetic pathway to the decahydroquinoline class of dendrobatid alkaloids.

Scheme 2. Biomimetic construction of the hydroquinoline ring system.

Scheme 3. Plausible mechanism for the formation of 5 .

Scheme 4. Biomimetic synthesis of decahydroquinoline cis-195A [(-)Pumiliotoxin C]. 
Entry for the Table of Contents (Please choose one layout)

((Catch Phrase))

M. Amat, ${ }^{\star}$ R. Griera, R. Fabregat, E. Molins, J. Bosch*

\section{Page - Page}

A Biomimetic Enantioselective Approach to the Decahydroquinoline Class of Dendrobatid Alkaloids**
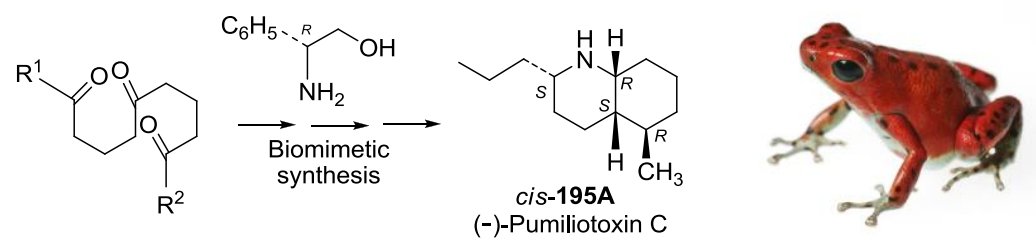

The hypothetical key step of the biosynthesis of the decahydroquinoline dendrobatid alkaloids from 1,5-polycarbonyl derivatives is mimicked by using $(R)$ phenylglycinol as a chiral latent form of ammonia in a double cyclocondensation reaction.

Keywords: Alkaloids · Biomimetic synthesis · Pumiliotoxin C . Decahydroquinolines · Phenylglycinol<smiles>[R]C1=C2CCCC(=O)OC2CCC([R])O1</smiles>

A

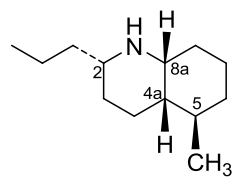

cis-195A

(-)-Pumiliotoxin C

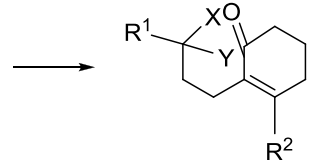

B $\quad X, Y=O$ $X=\mathrm{NH}_{2}, Y=\mathrm{H}$<smiles>[13CH3]</smiles><smiles>[R]C1CCC2C([R])CCCC2N1</smiles>

Scheme 1. A hypothetical biosynthetic pathway to the decahydroquinoline class of dendrobatid alkaloids. 


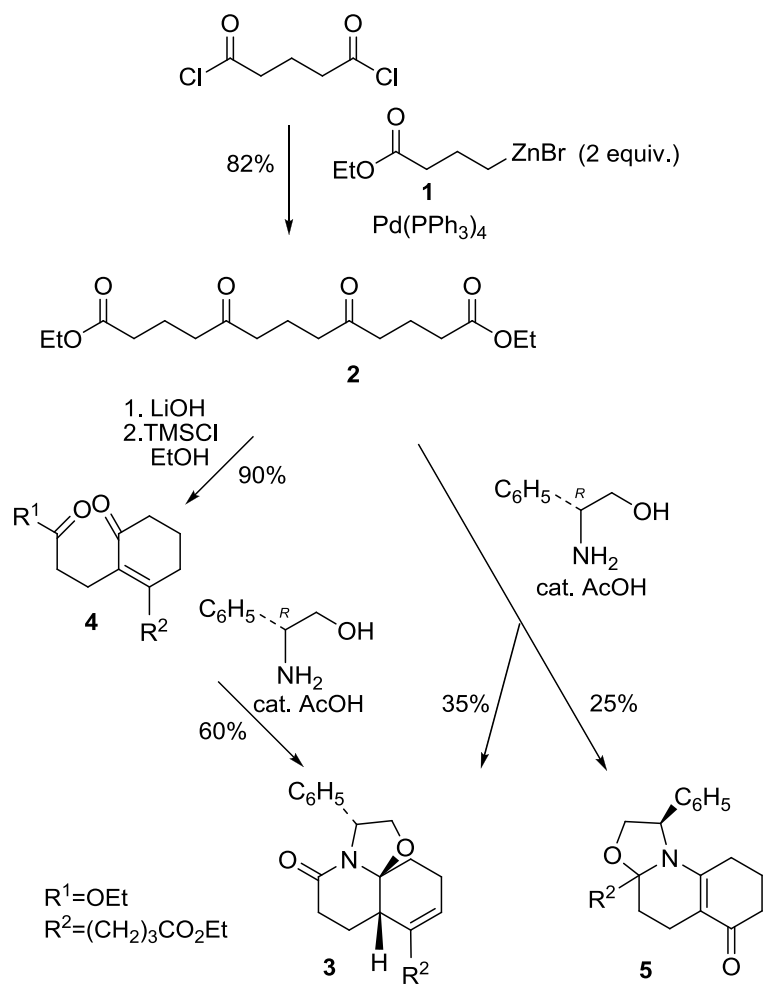

Scheme 2. Biomimetic construction of the hydroquinoline ring system.

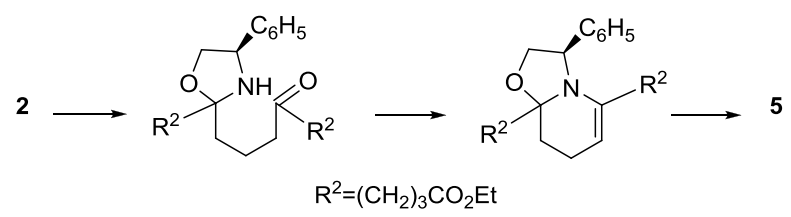

Scheme 3. Plausible mechanism for the formation of $\mathbf{5}$.
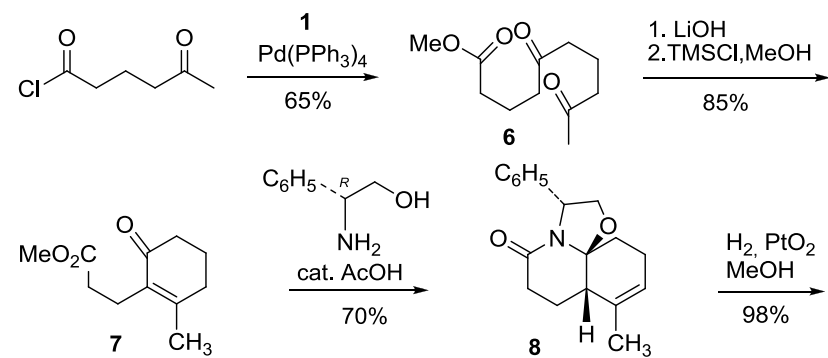

$\mathrm{H}_{2}, \mathrm{PtO}_{2}$

$\stackrel{\mathrm{MeOH}}{\longrightarrow}$
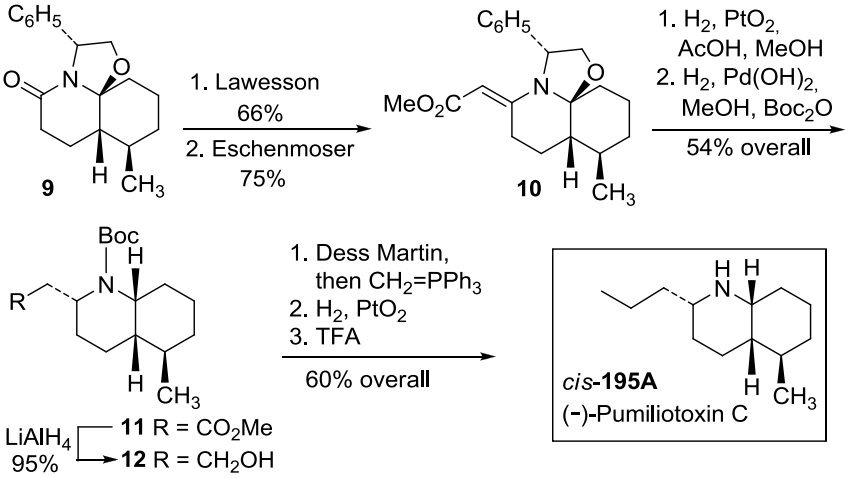

Scheme 4. Biomimetic synthesis of decahydroquinoline cis-195A [(-)-Pumiliotoxin C]. 
